\title{
A Study of the Relationship Between some Special Physicel Abilities and the Performance Effectiveness of Under Arm Hold to Throw over The Back Movement for Junior Wrestlers.
}

\author{
Thrwat Said Abdel-Hakim Abdel-Aty
}

Faculty of Sport Education for Boys, Alexandria University, Egypt.

\begin{abstract}
The research aimed to identify the relationship between some special physical abilities and the effectiveness of the throwing performance over the back for the beginner wrestlers under age 16. The researcher used the Survey Approach in this study, because of its suitability to the nature of the research. The Research Community was (35) beginners from the Club of El-Ghasal Company at Kafr El-Dawar, and (25) beginners from the Sports Area at Kafr El-Dawar, Behara. The most important results that: 1- There is a positive correlation between the Maximum Muscular Strength and the Level of Performing the Throws over the Back. 2) There is a negative correlation between the Maximum Muscular Strength and the Time of Throwing the Imaginary Opponent Model over the Back (S). 3) There is a negative correlation between the Muscular Strength of the two legs and the Time of Throwing the Imaginary Opponent Model over the Back (S). 4) There isn't any correlation between the Standing Long Jump (cm) and Time of Throwing the Dummy over the Back (S). 5) There is a positive correlation between the Explosive Power and the Level of Performing the Throws over the Back in Trunk Lean Test from Standing (10 S) (number) and in Test Number bridge in (10) seconds.
\end{abstract}

\section{Introduction:}

$\mathrm{T}$ The world witnessed a great development in all areas of life, including the sports field. The training process had a wide and variety development that resulted in high levels and fantastic records. The attention of sports specialists has been focused on developing the training process according to each sport, because every sport has its goals to be achieved through the training.

The physical abilities are important pillars that have an impact on developing various sports. Also the technical performance plays an important role in improving the physical activity. So, these abilities are very important in developing the athlete, especially in wrestling.

The integration between the physical and the technical abilities is an objective for all specialists in the field of sports. The (Static and Dynamic Maximum Strength, Explosive Power, Agility, and Flexibility) are considered as the basic elements in wrestling.

According to the researcher's experience and his working in wrestling field, he didn't find any study or research dealing with (Static and Dynamic Maximum Strength, Explosive Power, Agility, and Flexibility) in order to improve the throwing skill in Greco-Roman wrestling for beginners. This problem causes obvious defects in the performance of wrestlers while doing these important skills and no good wrestler can ignore these skills during the bout. So, the researcher wanted to study this problem to develop some solutions.
The wrestlers have different physical and technical abilities appearing during the bout. These specific physical abilities and the individual technical ones play an important role in getting advanced ranks. The researcher noted, as one concerning about wrestling training, that there is weakness in presenting the relation between the physical abilities and basic technical ones. So, the research problem came up to find the relation between (Strength and Explosive Power, Agility, and Flexibility) and the Throw skill over the back in Greco-Roman wrestling.

So, the research's importance is in finding the relation between the (Static and Dynamic Maximum Strength, Explosive Power, Agility, and Flexibility) and the Throw skill over the back in Greco-Roman wrestling. This research worked on finding training means and programs that work on developing the athletic performance. The Maximum Strength is one of the important abilities in wrestling because of its great importance in performing different grabs whether from standing or sitting positions. In order to develop wrestling, the wrestler has to develop this Maximum Strength.

Mohammad Hassan Allawi (1994) defined the Maximum Strength as "the maximal strength produced by the neuromuscular system in the case of muscle contraction, or as it the most important necessary physical ability for the various sports that require overcoming combat actions such as wrestling". Also, Bastawisi Ahmed (1990) defined it as "the exerted force during the maximum hard work of the muscles". Qassim Hassan Hussein (1998) defined also it as" the maximum strength produced by the muscles 
during the voluntary contraction". Mufti Ibrahim Hammad (2001) said that the Maximum Strength is" the maximal strength that can be produced by the muscle or the muscle group during the voluntary contraction" (13: 98) (2: 113) (11 110) (18: 169)

Mossad Ali Mahmoud and others (2001) said that wrestling achieve the balanced and symmetric growth for the body parts. Also wrestling give the wrestlers the ability to use all their body muscles efficiently from head to toe. It works on developing Strength, Agility, Flexibility, Muscular Endurance, Cardiovascular Endurance, Ability, Balance, Reaction speed and on improving the functions of the heart, lungs and blood vessels. (17: 7)

The Maximum Strength is absolutely necessary in the physical exercises and in overcoming the large combats. Also, it is considered as one of the necessary abilities for wrestler where he cannot do without it during the bout.

Flexibility is also considered as one of the most important element that plays a vital role in the motor performance. It is one of the main pillars for mastering any skill. Flexibility can be developed by the stretching exercises. These exercises aim to stretch the muscles, ligaments, tendons, and increase the movement range of the joints. These exercises are the most important methods for developing the flexibility. The other exercises can develop the flexibility, but these exercises must be associated with the strength exercises in order to have a balanced development.

DUMBACH (1984) said that "flexibility is one of the important and vitality elements in performing sports skills. He said also "flexibility is the maximum possible range of motion in a specific joint". (20: 5). Qassim Hassan Hussein (2002) showed that Flexibility is the key to the successful performance. The special skills, depending on a wide range of motion in joints, need flexibility. Also, flexibility can play an important role in: Learning a new intensive skill type. - Preventing injuries. - Developing the Power, Speed, Endurance and Agility abilities. We believe that less flexibility will obstruct performing these skills and it will lead to lose a lot of points. (12: 110)

Ali Abdul Aziz (1988) said that "Flexibility is the cornerstone of wrestling, because its skills (grabbing skills) require a wide and smooth range of motion. All that cannot be available in any movement unless there is a high flexibility in body's joints and fibers. (10: 502)

To be a skillful wrestler that will require integrated physical and technical exercises. So, any coach must care about the other abilities (Strength and Speed) while working on developing flexibility to achieve the comprehensive and integrated preparation.
Essam Abdul Khaliq (2008) showed that the importance of flexibility in wrestling manifests through the following points: Flexibility works with the other physical abilities on preparing the wrestler physically. Flexibility works on learning and mastering the skills quickly like (grabs). Flexibility helps to avoid injuries and minimize them (such as dislocation) Flexibility helps to delay the fatigue during the moving without cramps. Flexibility Contributes in performing large movements smoothly and impressively. So, the persons who are responsible for developing this sport must care about developing this ability (flexibility). (9:26)

INTERNATIONA (1991) showed that the most important mean to develop flexibility for wrestlers of Greco-Roman wrestling is the Bridge. So, the wrestler can be trained with another one (the wrestler has to turn over adversely from his natural position in order to protect himself. Also, he has to learn how to fall backwards by lowering the gravity point of the weight of the body). (21: 96)

Mahmoud Massad (1998) showed the importance of the Explosive Power in wrestling as one of the necessary physical abilities for developing the wrestler's fitness and for enhancing the competitiveness of the wrestler. (16:56)

Mohammed Ruby (2005) mentioned that the Explosive Power is one of the necessary physical abilities for developing of the wrestler's fitness, so he will be able to do most of the offensive, defensive duties and counterattack quickly and efficiently. (14: 130)

Muhammad Ruby (2008) emphasized that wrestling is characterized by the sudden and rapid change in positions during the bout. So, it requires high Explosive Power. (15: 211)

\section{- The Importance of arm Throw movement in Greco- Roman Wrestling:}

Doing the Grabs is the primary goal in the competition. The other aspects, whether physical or tactical, serve this goal. It gives superiority over an opponent and often determines his abilities. Each wrestler has an accumulate experience of many technical movements and grabs to be used successfully during the competition.

Without doubt, the diverse and comprehensive technical preparation is one of the most important requirements in wrestling. It is not enough for the wrestler to know the technical aspects of the grabs to win, but it's very important to know a lot of theoretical information about the wrestling laws.

The selection of the correct grabs and the time to be implemented in the bout contribute in the wrestler win. The implementation and the time of the grabs are assessed 
according to the international law of wrestling. The grabs were given a high score in the last modifications. The grabs also were classified as high technical skills and given (4) points to the wrestler who does it correctly, the highest scores in the grabs. (2: 71)

\section{The aim of the research:}

- the research aime to A study of the relationship between some special physical abilities (the Maximum Static, Dynamic Strength - the Explosive Power - Flexibility Agility )and the performance effectiveness of under arm hold to throw over theback movment for junior wrestlers

\section{Research Hypotheses:}

- There is a positive relationship between Maximum (Static, and Dynamic) Strength, Flexibility, Agility and performing under arm hold to throw over theback movment for junior wrestlers

\section{- Research Fields:}

\section{- Research Terminologies:}

- Maximum Strength: Abd-Allah Hussein Al-Lami (2004) defined it as" the maximal strength that can be produced by the neuromuscular system in the case of the maximum voluntary contraction. It is considered as the decisive factor in the sports activities which depend on very high combats." (8: 73)

- Greco-Roman wrestling: Hamdan Rahim al-Qubaisi (1999) defined it as "a style of amateur wrestling that is practiced worldwide. This style of wrestling forbids holds below the waist. This restriction results in an emphasis on throws because a wrestler cannot use trips to take an opponent to the ground, or avoid throws by hooking or grabbing the opponent's leg. " $(6: 51)$

Gamal Alaa El-ddin (1996) said that the time of performance contributes in evaluating the effectiveness of the performance. The time is one of the motives that lead to connect the various independent motor elements with the overall system during performing the skills. (4: 20 21)

\section{- Research Procedures:}

\section{- Research Methodology}

The researcher used the Survey Approach in this study, because of its suitability to the nature of the research.

\section{- Population Frame:}

The Research Community was (35) junior from the Club of El-Ghasal Company at Kafr El-Dawar, and (25) junior from the Sports Area at Kafr El-Dawar, Behara.

- Place Frame: Wrestling Hall of the Club of El-Ghasal Company and the Sports Area at Kafr El-Dawar.

-Time Frame: The period from 01/02/2014 till 02/20/2014.

\section{- Research Sample:}

The selection of the sample is an important thing in the scientific research. So, the researcher chose (60) junior wrestlers from the Club of El-Ghasal Company and the Sports Area at Kafr El-Dawar for the sports season 2014. All members of the sample have at least three years' experience in wrestling. The following table demonstrates the homogeneity of the sample.

Table (1)

(The Statistical Description of the Research Sample Data for the Primary Variables) Number $=60$

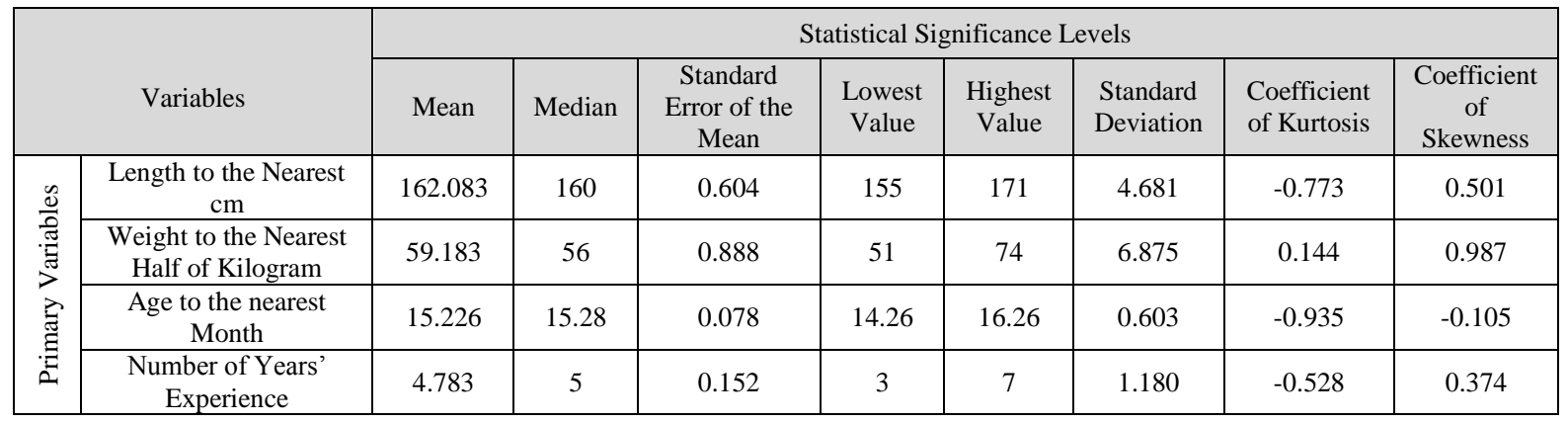

It's clear from the above table that the data of the sample is characterized with the normality and lack of dispersion. The coefficient of skewness was between (-0.105 to 0.987). It confirms that the data characterized with the normal distribution and the data belongs to a single homogeneous community.

\section{Methods and Tools Used in the Research:}


- Observation and Experimentation. - A Form Sheet for Collecting Data.

- Arabic and Foreign References and Books. - A Questionnaire.

- Mat of Wrestling. - Dummy (1/3 wrestler's weight)

- Medical scale to measure the weight. - Tape measure.

- (3) Stopwatch - Dynamometer Device Calculator

\section{pilot study :}

This pilot study started from 02/01/2014 till 5/2 / 2014 in Club of El-Ghasal Company at Kafr El-Dawar. This experiment included 5 beginner wrestlers; they were excluded from the original experiment. This study aimed to:

- Ensure from the appropriation of the proposed test for the research sample.

- Measure the required time to do the tests. - Train the Assistant Team.

- Provide, check the tools and overcome the mistakes, if there is any.

- Ensure from the ability of the research sample to do the tests without any obstacles.

\section{Main study:}

The researcher conducted the measurements and tests on the sample in the period from 02/05/2014 until 20/02/2014.

\section{- Tests Used in the Research:}

First: The Tests of the Maximum Static and Dynamic Strengths:

- Test of the Right and Left Hand Grip Strength to the nearest $\mathrm{kg}$.

- Test of the Static Maximum Strength for the back muscles $(\mathrm{kg})$.
- Test of the Static Maximum Strength for the muscles of the leg $(\mathrm{kg})$.

- Test of the Static Maximum Strength for the working muscles of the Throws Skill over the Back (kg).

- Test of the Dynamic Maximum Strength for the working muscles of the Throws Skill over the Back (kg).

Second: The Tests of the Special and General Explosive Power:

- Standing Long Jump Test (cm).- Standing Vertical Jump Test (cm).

- Test Time of Throwing the Dummy for three repetition (S). - Test Time of the Throws skills from over the back $(\mathrm{S})$.

Third: Special and General Agility Fitness tests:

- squat thurst (perpee) (10 S) (number). - Test Number bridge in (10) seconds .

\section{Fourth: Special Flexibility Tests:}

- Vertical Distance Test (cm)for bridge . Horizontal Distance Test (cm) for bridge. (3)

Fifth: Technical Tests:

- Test Time of Throwing the Dummy over the back (S)(time of one repetition).

- Test Score of performing theunder throw over the back (Point). (3)

\section{Statistical Means:}

Both of Wadih Yassin , Mohammed Hassan al-Obeidi (1996) agreed on using the following statistical methods for analyzing the data:

- Mean - Median - Standard Deviation Coefficient of Variation

- Coefficient of Skewness - Pearson Coefficient (19: 102) 


\section{Presenting and Discussing the Results:}

\section{The Relationship between the Physical Abilities and the Technical Performance:}

Table (2)

(Coefficient of Correlations Showing the Relationship between Variables of the Maximum Muscular Strength and the Technical Performance for Wrestlers) Number $=60$

\begin{tabular}{|c|c|c|c|}
\hline \multirow{2}{*}{ Physical Abilities } & \multicolumn{2}{|c|}{ Technical Variables } \\
\hline \multirow{2}{*}{ Grip Strength } & Right & $\begin{array}{c}\text { Time of Throwing the Dummyl } \\
\text { over the Back (S) }\end{array}$ & $\begin{array}{c}\text { Level of Performing the Throws } \\
\text { over the Back }\end{array}$ \\
\cline { 2 - 4 } & Left & -0.239 & $0.363^{* *}$ \\
\hline Stretched Back Muscles (kg) & $-0.590^{* *}$ & 0.219 \\
\hline Stretched Legs Muscles (kg) & $-0.639^{* *}$ & $0.406^{* *}$ \\
\hline $\begin{array}{c}\text { Dynamic Maximum Strength for the working muscles of } \\
\text { the under arm hold to throw over theback movment (kg). }\end{array}$ & $-0.356^{* *}$ & $0.574^{* *}$ \\
\hline
\end{tabular}

** At the significant level $0.01=0.325 \quad *$ At the significant level $0.05=0.250$

It's clear from the previous table that there are Significant Coefficients of Correlation at the level 0.01 between the Maximum Muscular Strength and the Technical Performance for Wrestlers. There is a positive correlation between the Maximum Muscular Strength and the Level of Performing the Throws over the Back at (0.363 to 0.574). There isn't any correlation between the Left Hand Grip Strength and Level of Performing the Throws over This value isn't significant at level 0.05 . While, there is a negative correlation between the Maximum Muscular Strength and the Time of Throwing the Imaginary Opponent Model over the Back at (0.356 to 0.787). Also, there isn't any correlation between the Right Hand Grip Strength and Time of Throwing the Imaginary Opponent Model over the Back, where the coefficient of correlation the Back, where the coefficient of correlation was (0.219).

Table (3)

(Coefficient of Correlations Showing the Relationship between the Muscular Strength of the two legs and the Technical Performance for Wrestlers) Number=60

\begin{tabular}{|c|c|c|}
\hline \multirow{2}{*}{ Technical Variable } & \multicolumn{2}{|c|}{ Technical Variables } \\
\cline { 2 - 3 } Physical Abilities & $\begin{array}{c}\text { Time of Throwing the } \\
\text { Dummy over the Back }(\mathrm{S})\end{array}$ & $\begin{array}{c}\text { Level of Performing the } \\
\text { Throws over the Back }\end{array}$ \\
\hline Standing Long Jump Test $(\mathrm{cm})$ & -0.175 & $0.430^{* *}$ \\
\hline Standing Vertical Jump Test (cm & $-0.352^{* *}$ & $0.395^{* *}$ \\
\hline
\end{tabular}

** At the significant level $0.01=0.325$

It's clear from the previous table that there are Significant Coefficients of Correlation at the level 0.01 between the Muscular Strength of the two legs and the Technical Performance for Wrestlers. There is a positive correlation between the Muscular Strength of the two legs and the Level of Performing the Throws over the Back at ( 0.430 to $0.395)$, respectively. While, there is a negative correlation between the Muscular Strength of the two legs and the Time of Throwing the Imaginary Opponent Model over the Back at (0.352). Also, there isn't any correlation between the Standing Long Jump ( $\mathrm{cm}$ ) and Time of Throwing the Imaginary Opponent Model over the Back, where the coefficient of correlation was (0.239). This value isn't significant at level 0.05 
Table (4)

(Coefficient of Correlations Showing the Relationship between the Explosive Power and the Technical Performance for Wrestlers) Number $=60$

\begin{tabular}{|c|c|c|}
\hline \multirow{2}{*}{ Technical Variable } & \multicolumn{2}{|c|}{ Technical Variables } \\
\cline { 2 - 3 } Physical Abilities & $\begin{array}{c}\text { Time of Throwing the } \\
\text { Dummy over the Back (S) }\end{array}$ & $\begin{array}{c}\text { Level of Performing the Throws } \\
\text { over the Back }\end{array}$ \\
\hline Time of Throwing the Dummy for three repetition (S). & $0.464^{* *}$ & $-0.428^{* *}$ \\
\hline Test Time of the under arm hold to throw over theback (S). & $0.518^{* *}$ & $-0.466^{* *}$ \\
\hline squat thurst (perpee) (10 S) (number) & $-0.255^{*}$ & $0.668^{* *}$ \\
\hline Test Number bridge in (10) seconds & $-0.584^{* *}$ & $0.404^{* *}$ \\
\hline
\end{tabular}

** At the significant level $0.01=0.325$

* At the significant level $0.05=0.250$

It's clear from the previous table that there are Significant Coefficients of Correlation at the level 0.01 between the Explosive Power and the Technical Performance for Wrestlers. There is a positive correlation between the Explosive Power and the Level of Performing the Throws over the Back in Trunk Lean Test from Standing (10 S) (number) and in Test Number bridge in (10) seconds at (0.668 to 0.404$)$, respectively. While, there is a negative correlation between the variables of (Time of Throwing the Imaginary opponent Model for three times (S), Time of the Throws skills from over the back (S)) and the Level of Performing the Throws over the Back at $(0.428$ to

Table (5)
0.466). There is a positive correlation between the Explosive Power and Time of Throwing the Imaginary Opponent Model over the Back (S)in (Time of Throwing the Imaginary opponent Model for three times (S),Test Time of the Throws skills from over the back (S)) at (0.464 and 0.518), respectively. While, there is a negative correlation between the variables of (Trunk Lean Test from Standing (10 S) (number), Test Number bridge in (10) seconds) and Time of Throwing the Imaginary Opponent Model over the Back (S) at (0.255 to 0.584), respectivel

(Coefficient of Correlations Showing the Relationship between the Flexibility Variables and the Technical Performance for Wrestlers) Number=60

\begin{tabular}{|c|c|c|}
\hline \multirow{2}{*}{ Technical variables } & \multicolumn{2}{|c|}{ Technical Variables } \\
\cline { 2 - 3 } Physical Abilities & $\begin{array}{c}\text { Time of Throwing the } \\
\text { Dummy over the Back (S) }\end{array}$ & $\begin{array}{c}\text { Level of Performing the } \\
\text { Throws over the Back }\end{array}$ \\
\hline Vertical Distance for Bridge & $-0.559^{* *}$ & $0.492^{* *}$ \\
\hline Horizontal Distance for Bridge & $0.325^{* *}$ & $-0.438^{* *}$ \\
\hline
\end{tabular}

** At the significant level $0.01=0.325$

It's clear from the previous table that there are Significant Coefficients of Correlation at the level 0.01 between the Flexibility Variables and the Technical Performance for Wrestlers. There is a positive correlation between the Flexibility and the Level of Performing the Throws over the Back (Vertical Distance) at (0.492). While, there is a negative correlation between the variable of Horizontal Distance and the Level of Performing the Throws over the Back at (0.438). There is a positive correlation between the Flexibility and the Time of Throwing the Imaginary Opponent Model over the Back (S) in (Horizontal Distance) at (0.325). While, there is a negative correlation between the variables of (Vertical Distance)and the Time of Throwing the Imaginary Opponent Model over the Back $(\mathrm{S})$ at (0.255 and 0.559)
* At the significant level $0.05=0.250$

These results are consistent with what explained by Petrov (1989) that trainers must care about specific flexibility distinctively, where the wrestler, who possesses the other Physical Abilities and lacks the flexibility one, won't do these special grabs). (22: 98)

Also, these results are consistent with the results of studies of both Hamdan Rahim Raja and Ali Salman (2002) that there are variances in the levels of flexibility for the wrestlers in general. (7)

The results of this study are consistent with the results of a study of Hussein Saget Alhjami (2011) that the Maximum Strength of the arms' muscles has great importance in performing the skills. Also, the Maximum Strength of the legs' muscles has a great impact in performing the skills. 
The Maximum Strength of the back's muscles affect effectively in performing the skills. (5)

\section{Conclusions:}

1. There is a positive correlation between the Maximum Muscular Strength and the Level of Performing the Throws over the Back.

2. There is a negative correlation between the Maximum Muscular Strength and the Time of Throwing the Imaginary Opponent Model over the Back (S).

3. There isn't any correlation between the Right Hand Grip Strength and the Time of Throwing the Dummy over the Back (S).

4. There is a positive correlation between the Muscular Strength of the two legs and the Level of Performing the Throws over the Back.

5. There is a negative correlation between the Muscular Strength of the two legs and the Time of Throwing the Dummy over the Back (S).

6. There isn't any correlation between the Standing Long Jump (cm) and Time of Throwing the Dummy the Back (S).

7. There is a positive correlation between the Explosive Power and the Level of Performing the Throws over the Back in Trunk Lean Test from Standing (10 S) (number) and Test Number bridge in (10) seconds

8. There is a negative correlation between the variables of (Time of Throwing the Dummy for three times (S), Time of the Throws skills from over the back (S)) and the Level of Performing the Throws over the Back.

9. There is a positive correlation between the Explosive Power and Time of Throwing the Dummy over the Back (S)in (Time of Throwing Dummy for three times (S),Test Time of the Throws skills from over the back (S)).

10. There is a negative correlation between the variables of (Trunk Lean Test from Standing (10 S) (number), Test Number bridge in (10) seconds) and Time of Throwing the Dummy the Back (S).

11. There is a positive correlation between the Flexibility and the Level of Performing the Throws over the Back (Vertical Distance) for bridge.
12. There is a negative correlation between the variable of Horizontal Distance and the Level of Performing the Throws over the Back.

13. There is a positive correlation between the Flexibility and the Time of Throwing the Dummy over the Back (S) in (Horizontal Distance).

14. There is a negative correlation between the variables of (Vertical Distance) and the Time of Throwing the Dummy over the Back (S).

\section{Recommendations:}

- The need to conduct periodic tests for flexibility and agility and link these tests the other skills. Design specific standards for wrestler.

- The need to provide the modern equipment inside the sporting clubs and put them in the service for the training process.

- Coaches must pay attention to develop the techniques that worth high points.

- The need to take the physical tests as a basis for building the training program in order to develop the technical performance in Greco- Roman wrestling.

- Focus on designing training modules to develop the maximum Strength in order to improve the performance of Grabs.

- The need to pay attention in the training programs to the Maximum Strength and the Explosive Power.

- Work on developing the flexibility and agility through special exercises.

- Conduct training sessions to control the training loads (intensity, size, and break), taking into account the gradualism in training loads.

\section{References}

\section{First: Arabic References:}

1. International Law of Wrestling (Translation), Adil Ibrahim Mustafa, Mustafa Ahmed Abdel Azim, Cairo 1993.

2. Bastawisi Ahmed Principles and Theories of Sports Training, Cairo, Dar El-Fakr Araby 1990

3. Thrwat Said Abdel- Hakim The Effectiveness of a Training Program to Develop the Performance Time of Doing some Arm Throws Movements and Its relationship to the Results of the Matches for 
the wrestlers under age 16. Master Thesis, unpublished, Faculty of Physical Education for Boys, Alexandria University, in 2006.

4. Jamal Mohammed Aladdin Biomechanical Approach of the Level of Mastery the Skills in the Field of Sports, curriculums for the students of the doctoral stage 1996.

5. Hussein Manati Sagt Alhjami The Maximum Strength and its Relationship to the performance of some Grabs from above the Chest in GrecoRoman Wrestling, Scientific Journal of Physical Education, Volume IV, Issue IV, Karbala University / Faculty of Physical Education, 2011.

6. Hamdan Rahim al-Qubaisi A Study for some Basic Special Determinants as an Indicator of Selection in the Greco-Roman Wrestling, Baghdad University, Journal of Physical Education, 1999.

7. Hamdan Rahim Raja and Ali Salman The Level of Flexibility and its Relationship to the successful Performance for some Grabs in Greco-Roman Wrestling, Journal of the Faculty of Physical Education, University of Baghdad, Volume 16, Issue 3, 2002.

8. Abdullah Hussein al-Lami The Scientific Basis for the Sports Training, Baghdad. Dar El-Kotob, Edition 1, 2004.

9. Essam El-Din Abdul Khaliq Sports training; Theories and Applications, Egyp, Dar El-Fakr 2008 .

10. Ali Abdul Aziz The Effect of Flexibility on the performance in Wrestling, Theories and Applications Journal, second edition, 1988.

11. Qassim Hassan Hussein Basics of Athletic Training, Oman, Dar El-Fakr, 1998.

12. Qassim Hassan Hussein Fitness and Technique Training for Sports, Mosul, Dar El-Kotob for publishing 2002.

13. Mohammad Hassan Allawi The Science of Sports Training, Edition 3, Cairo, Dar El-Fakr 1994.

14. Mohammad Reda Roby The Training Principles of the Freestyle Wrestling, $1^{\text {st }}$ edition, Mahy Center for Publishing, Alexandria, 2005.

15. Mohammad Reza Roby Learning Encyclopedia in Greco-Roman Wrestling, Mahy Center for Publishing, Alexandria, 2008.
16. Massad Ali Mahmoud the Theoretical and Practical Basis for Greco-Roman and Freestyle Wrestling, Mansoura University, Mansoura 1998.

17. Massad Ali Mahmoud, Mohammad Reza Roby and Hassan Abdel-Salam Mahfouz The Theoretical and Practical Basis for Greco-Roman and Freestyle Wrestling, Faculty of Physical Education for Boys in Alexandria 2001.

18. Mufti Ibrahim Hammad Sports training and planning and implementation of Jaisalmer, Egypt , the Arab Thought Dar 0.2001 m .

19. Wadih Yassin and Mohammed Hassan al-Obeidi Applications in Physical Education Researches, Mosul, Dar El-Kotob for Printing and Publishing, 1996.

\section{Second: Foreign References:}

20. Dumbach, A8ionsn, W.R Exploring Sport Seris Wresting Law, Awme Bvown Co. Pubiishvs1984 $\mathrm{P}, 5$

21. Internationa Auies Wrestiing. Puiishen Intenation Amater Wrestiing Fedevation Fila. Lausanna. 1991.P-96

22. Petrov. R. Free Style And Greco - Roman Wrestling, Published By Fila, Yogoslavia, 1989. 
